\title{
Stereotactic ablative radiotherapy (SABR) as primary, adjuvant, consolidation and re- treatment option in pancreatic cancer: scope for dose escalation and lessons for toxicity
}

\author{
Christy Goldsmith ${ }^{1 *}$ (D, P. Nicholas Plowman ${ }^{2,3}$, Melanie M. Green ${ }^{4}$, Roger G. Dale ${ }^{4}$ and Patricia M. Price ${ }^{2,4}$
}

\begin{abstract}
Background: Stereotactic ablative radiotherapy (SABR) offers an alternative treatment for pancreatic cancer, with the potential for improved tumour control and reduced toxicity compared with conventional therapies. However, optimal dose planning and delivery strategies are unelucidated and gastro-intestinal (Gl) toxicity remains a key concern.

Methods: Patients with inoperable non-metastatic pancreatic cancer who received CyberKnife ${ }^{\oplus}$ SABR (18-36 Gy) in three fractions as primary, adjuvant, consolidation or re-treatment options were studied. Patient individualised planning and delivery variables were collected and their impact on patient outcome examined. Linear-quadratic $(L Q)$ radiobiology modelling methods were applied to assess SABR parameters against a conventional fractionated radiotherapy schedule.

Results: In total 42 patients were included, 37 (88\%) of whom had stage T4 disease. SABR was used $>6$ months post-primary therapy to re-treat residual disease in 11 (26.2\%) patients and relapsed disease in nine (21.4\%) patients. SABR was an adjuvant to other primary therapy for 14 (33.3\%) patients and was the sole primary therapy for eight (19.0\%) patients. The mean (95\% Cl) planning target volume (PTV), prescription isodose, percentage cover, minimum dose to PTV and biological effective dose (BED) were 76.3(63.8-88.7) cc, 67.3(65.2-69.5)\%, 96.6(95.5-97.7)\%, 22.3(21.023.6) Gy and 50.3(47.7-53.0) Gy, respectively. Only 3/37 (8.1\%) patients experienced Grade 3 acute toxicities. Two (4.8\%) patients converted to resectable status and median freedom-from-local-progression (FFLP) and overall survival (OS) were 9.8 and 8.4 months, respectively. No late toxicity was experienced in 27/32 (84.4\%) patients; however, four (12.5\%) patients - of whom two had particularly large PTV, two had sub-optimal number of fiducials and three breached organ-at-risk (OAR) constraints - showed Grade 4 duodenal toxicities. Longer delivery time, extended treatment course and reduced percentage coverage additionally associated with late toxicity, likely reflecting parameters typically applied to riskier patients. Larger PTV size and longer treatment course associated with OS. Comparator regimen LQ modelling analysis indicated $50 \%$ of patients received minimum PTV doses less potent than a conventional radiotherapy regimen, indicating scope for dose escalation.

(Continued on next page)
\end{abstract}

\footnotetext{
* Correspondence: christy.goldsmith@gstt.nhs.uk

'Guys and St Thomas' NHS Foundation Trust, London, UK

Full list of author information is available at the end of the article
}

(c) The Author(s). 2018 Open Access This article is distributed under the terms of the Creative Commons Attribution 4.0 International License (http://creativecommons.org/licenses/by/4.0/), which permits unrestricted use, distribution, and reproduction in any medium, provided you give appropriate credit to the original author(s) and the source, provide a link to the Creative Commons license, and indicate if changes were made. The Creative Commons Public Domain Dedication waiver (http://creativecommons.org/publicdomain/zero/1.0/) applies to the data made available in this article, unless otherwise stated. 
(Continued from previous page)

Conclusion: The results demonstrate the value of SABR for a range of indications in pancreatic cancer. Dose escalation to increase BED may improve FFLP and OS in inoperable, non-metastatic disease: however concomitant enhanced stringency for duodenal protection is critical, particularly for patients where SABR is more challenging.

Keywords: Stereotactic ablative radiotherapy (SABR), Cyberknife ${ }^{\circledR}$, Pancreatic cancer, Radiobiology, Dose escalation, Local control, Toxicity, Survival

\section{Background}

Pancreatic cancer is characterised by debilitating symptoms caused by local disease advance, high rates of metastatic progression and dismally close incidence and mortality rates. Median overall survival (OS) from diagnosis for all patients is less than 5 months, $\sim 20 \%$ of patients overall survive more than 1 year and $\sim 5 \%$ survive more than 5 years [1-4]. Standard treatment options include single or multi-agent chemotherapy or chemoradiotherapy. For the small minority of patients diagnosed with earlier stage resectable disease, radical surgical resection offers the best chance of long-term survival with reported 5-year survival rates of $\sim 20 \%$ [5]. However, the disease is typically diagnosed at more advanced stages: $\sim 45 \%$ of patients present with metastatic disease that has a median OS of $\sim 2-5$ months, and $\sim 30 \%$ present with inoperable localized or locally advanced pancreatic cancer (LAPC) that has an intermediate status and prognosis [1-4]. For the latter subset of patients, conversion to resectability currently offers the best outcome [5-7]: nevertheless, median OS reported in LAPC randomised trials remains poor at 7-15 months [8-10].

Modern conformal radiotherapy has a central role in pancreatic cancer disease control to: 1) palliate symptoms and prevent local progression that causes morbidity and may be causal of death [11]; 2) increase the chances of achieving secondary resectability [6, 7]; and 3 ) extend median survival time [12-15]. However, conventional chemoradiotherapy regimens can be long ( 5.5 weeks) and arduous with only a modest or no overall survival gain [16]. Furthermore, the radiation doses that can be delivered safely are limited by toxicity to adjacent abdominal structures such that local control rates can be low $[8,15,17,18]$, repeat treatment upon relapse is inhibited, and treatment toxicity may be high and exacerbated by concomitant chemotherapeutics [14, 19-22].

Stereotactic ablative body radiotherapy (SABR) may be used as an alternative, adjunct, consolidation or retreatment option to conventional therapies in pancreatic cancer. High dose radiotherapy can be delivered in conveniently few fractions, with rapid dose fall-off outside the delineated tumour volume [23, 24]. This offers the potential for increased local tumour control and reduced toxicity, and additionally introduces the valuable possibility of tumour re-irradiation. Due to the highly conformal target volumes delineated, the high doses delivered and the proximity of adjacent radiosensitive organsat-risk (OAR - duodenum, stomach, small bowel, liver, kidneys and spinal cord), accurate on-treatment tumour targeting is imperative.

Previous studies have pioneered the use of SABR in pancreatic cancer in various regimens, including as a single boost adjunct to chemotherapy or chemoradiotherapy or for re-treatment following local failure [2022, 25-37]. The majority have shown relative efficacy for local control with reasonable toxicity, as well as benefits such as convenience and good pain relief [37]. Furthermore, receipt of SBRT compared with conventionally fractionated radiotherapy has shown significantly improved OS for locally advanced disease [38]. However, comparisons, interpretations and treatment optimisation of SABR in pancreatic cancer have been difficult as different planning, delivery and dosimetry methodologies have been used. As a result, local control has been reported as excellent in some studies [22, 25, 29, 31], but not in others $[20,21]$ and toxicity has been reported to be low in some studies [26, 33], but significant or unacceptable in others [20-22, 25, 28, 36, 39]. With the aim of increasing understanding and enabling treatment improvements for inoperable, non-metastatic pancreatic cancer, in our real-world series of patients we sought to: 1) review patient outcomes following SABR treatment for a range of indications 2) comprehensively examine the contribution of patient, planning, delivery and radiobiological variables upon the toxicity and efficacy of fractionated SABR and 3) use radiobiological modelling to compare SABR treatment to a conventional comparator regimen.

\section{Methods}

\section{Patients and data collection}

Pancreatic cancer patients referred to The CyberKnife ${ }^{\circ}$ Centre at The Harley Street Clinic for SABR treatment from March 2009 - October 2012 were included. For comparative radiobiological and outcome purposes, only patients with inoperable status and no detectable metastases (i.e. those with localized or locally advanced disease that was unresectable, who had a prognosis intermediate to resectable and metastatic disease), who were treated in three fractions, were studied. Patient, 
tumour, treatment planning and delivery parameters were collected at the time of treatment. Patients were longitudinally followed and toxicity and outcome data were acquired at follow-up clinic appointments.

\section{Treatment}

SABR was delivered with the CyberKnife ${ }^{\mathrm{rw}}$ robotic radiosurgery system (Accuray Corporation, Sunnyvale, CA, USA) [40]. In the majority of cases, following percutaneous implantation of gold fiducial tumour markers (Cybermark, CIVCO Medical Solutions, Iowa, USA) under computed tomography $(\mathrm{CT})$ or endoscopic ultrasound (EUS) guidance, the Synchrony ${ }^{\circ}$ (Accuray ${ }^{\circ}$ Corporation, Sunnyvale, CA, USA) near real-time kilovoltage imaging system was used to achieve dynamic radiation delivery adaptive to patient and tumour movement.

Planning CT scans were performed at least one week after fiducial placement. Patients were advised to drink $300 \mathrm{mls}$ of cold water 30 mins before scanning to promote duodenal filling. Patients were scanned supine in the treatment position and immobilised with an individualised Vac-Lok cushion (Civco Medical Solutions, Iowa, USA) to support the arms and upper torso. Knee and ankle supports were used where needed. A non-contrast CT was performed in all patients and unless contra-indicated by poor renal function, a contrast CT scan was also performed to aid target definition following intravenous administration of $100 \mathrm{mls}$ Omnipaque. Scans were performed in mid-breath hold and were acquired with $1.25 \mathrm{~mm}$ slice thickness. The field-of-view encompassed the entire circumference of the body contour with coverage from $15 \mathrm{~cm}$ above the most superior fiducial to $15 \mathrm{~cm}$ below the most inferior fiducial. Target localisation was performed on the CyberKnife ${ }^{\circ}$ MultiPlan Treatment Planning System (Accuray Inc. Sunnyvale, CA, USA). Treatment was planned on the noncontrast CT scan which was fused with the contrast CT to aid target localisation. Where available, pre-treatment combined 18-fluorodeoxyglucose positron emission tomography and CT $\left({ }^{18}\right.$ F-FDG-PET/CT $)$ scan was also fused with the planning CT. Gross tumour volume (GTV) was outlined by the treating clinician, reviewed by a radiologist where appropriate and expanded with an isocentric margin of $2-3 \mathrm{~mm}$ to form the planning target volume (PTV).

In two palliative cases where fiducial tracking was not performed, patients were planned and monitored with an internal tumour volume (ITV) and XSight ${ }^{\circ}$ Spine Tracking (Accuray Corporation, Sunnyvale, CA, USA) approach. Planning CT scans were acquired in free-breathing, maximal inspiration and maximal expiration respiratory phases. An internal target volume (ITV) was constructed to incorporate maximal GTV excursion with respiration and XSight ${ }^{\circ}$ Spine tracking was used throughout treatment to assure reproducible patient body anatomy positioning.

For all patients, the duodenum, stomach, small bowel, liver, kidneys and spinal cord were outlined and treated as OAR. The duodenum was considered the primary OAR and constraints were applied as previously published [41, 42]. The preferred OAR dose constraints for three fraction SABR (applied when feasible) are given in Table 1. Tighter constraints were applied if previous radiotherapy had been given. Patients were prescribed 18-36 Gy in three fractions, with total dose influenced by the proximity of dose-limiting OAR (primarily duodenum and stomach) and any prior radiotherapy received. The prescription isodose line was chosen to provide optimum coverage of the target volume whilst respecting OAR constraints. Tumour definition, normal tissue constraints and final treatment plan were approved by the consultant radiation oncologist and attending medical physicist.

Prior to each treatment fraction, patients were premedicated with prophylactic ondansetron $4 \mathrm{mg}$ and metoclopramide $10 \mathrm{mg}$ orally (unless contra-indicated). Patients drank $300 \mathrm{mls}$ of water and set-up was performed as per CT planning. A non-contrast mid-breath hold CT scan was performed on Day 1 for patients with implanted fiducial markers to assess fiducial stability. This scan was fused with the planning CT and was assessed on the MultiPlan ${ }^{\circ}$ System (Accuray Corporation, Sunnyvale, CA, USA), prior to radiation delivery to ensure that fiducial placement was maintained. Once the CyberKnife ${ }^{\circ}$ physicist and treating physician were satisfied that the fiducial arrangement on the Day $1 \mathrm{CT}$ matched that of the planning CT, the GTV and PTV contours were overlaid on the Day 1 CT to check contours appropriately covered the tumour target, with no discernible differences to adjacent OAR (e.g. stomach/ duodenal filling or tumour growth) impacting target coverage. Following this check, most patients were treated on 3 consecutive weekdays; in all cases treatment was completed within 7 days.

\section{Follow-up}

Patients were clinically reviewed 3-months after treatment, then at 6-month intervals thereafter when post-treatment $\mathrm{CT}$ scans were acquired. Toxicity was assessed using Common Terminology Criteria for Adverse Events version 3 (CTCAEv3). Local and distant failures were determined by an independent reporting radiologist and the treating physician using radiological information. Local control was defined as stable or decreased tumour size, local failure was defined by an increase in tumour size and distant failure was defined as the appearance of new lesions on CT or PET scan. 
Table 1 OAR dose constraints applied for three fraction SABR in this study

\begin{tabular}{|c|c|c|c|c|c|c|c|}
\hline & D0.035 cc & D0.1 cC & D10.0 cc & $\mathrm{D} 5.0 \mathrm{cc}$ & V12 Gy & V15 Gy & V21 Gy \\
\hline Duodenum & $\leq 22.2 \mathrm{~Gy}$ & - & $\leq 11.4 \mathrm{~Gy}$ & $\leq 16.5 \mathrm{~Gy}$ & - & - & - \\
\hline Stomach & $\leq 22.2 \mathrm{~Gy}$ & - & $\leq 16.5 \mathrm{~Gy}$ & - & - & - & - \\
\hline Small Bowel & $\leq 25.2 \mathrm{~Gy}$ & - & - & $\leq 17.7 \mathrm{~Gy}$ & - & - & - \\
\hline Liver & - & - & - & - & - & $\leq 50 \%$ & $\leq 30 \%$ \\
\hline Kidneys (separate) & - & - & - & - & $\leq 25 \%$ & - & - \\
\hline Kidneys (together) & - & - & - & - & - & $\leq 35 \%$ & - \\
\hline Spinal cord & $\leq 21.0 \mathrm{~Gy}$ & $\leq 18.0 \mathrm{~Gy}$ & - & - & - & - & - \\
\hline
\end{tabular}

Note: For all pancreatic patients treated with $\leq 30$ Gy in three fractions, we have since revised our duodenal D0.035 cc constraint to the higher limit of 24 Gy, but additionally now use D1.0 $\mathrm{cc}<31.4 \mathrm{~Gy}$

\section{BED calculation and radiobiological modelling}

The biological effective dose (BED) received by each patient was calculated simply as:

$$
\mathrm{BED}=\mathrm{D} \times\left[1+\frac{d}{\frac{\alpha}{\beta}}\right]
$$

where $D$ is the total dose delivered, $\mathrm{d}$ is the dose per fraction and $\alpha / \beta$ is the assumed fractionation factor. For pancreatic tumour, the radiobiological assumption was $\alpha / \beta=10$ Gy. For normal tissues the radiobiological assumption was $\alpha / \beta=3$ Gy. Comparison between SABR and conventional radiotherapy schedules was carried out using the linear-quadratic (LQ) model modified to account for tumor repopulation. The conventional radiotherapy comparator schedule used was 50.4 Gy in 28 fractions over a total period of 5.5 weeks (37 days). For the calculation of iso-effective SABR schedules a repopulation correction was applied to the BED calculation formula [43, 44], where for pancreatic tumour the radiobiological parameter assumptions used were: doubling time $=42$ days, $\mathrm{k}=0.5$ Gyday $^{-1}$ and repopulation was assumed to be operative throughout the entire treatment. As the majority of SABR treatments were completed within 3 days, a fixed repopulation correction of $3 \times 0.5$ Gy $=1.5$ Gy was used.

\section{Statistical analysis}

The Chi-squared test or ANOVA analysis was used to determine the association between planning and delivery variables and toxicity. Kaplan-Meier analysis was used to calculate freedom-from-local-progression (FFLP), progression-freesurvival (PFS) and overall survival (OS), beginning from the start of SBRT treatment and censoring patients lost to follow-up. Log-rank analysis was used to assess the impact of factors on FFLP and OS. The Cox proportional hazard model, adjusted for all variables, was used to assess the impact of multi-variate factors upon FFLP and OS.

\section{Results}

Patient, tumour and treatment purpose characteristics (Table 2)

A total of 42 patients were included, with median (range) patient age of 64 (42-85) years. The majority of patients had stage T4 disease located in the head of the pancreas. The reported reasons for SABR as the sole primary treatment (8 patients) were poor performance status (PS), co-morbidity and patient choice. SABR was considered as an adjuvant when it was used within 6 months of standard therapies (14 patients). SABR was used 6 months- 3 years after primary therapy as a consolidation or re-treat option for residual or relapsed local disease in 20 patients.

\section{SABR planning and delivery variables (Table 3)}

The majority of patients had 3-4 stably implanted fiducials (64\%) and received treatment on 3 consecutive days (88\%). PTV size ranged from 15.8-193.6 cc, percentage cover ranged from $79.9-99.5 \%$, treatment duration was $3-7$ days, treatment delivery time ranged from 36 to 162 mins, BED ranged from 23.4-79.0 Gy and the mean minimum dose to PTV ranged from 11.07-34.45 Gy. Mean and 95\% confidence interval $(\mathrm{CI})$ values are given in Table 2. Alternative planning and motion management strategies (ITV and $\mathrm{XSight}^{\circ}$ Spine) were necessary in two palliative patients.

\section{Acute and late treatment toxicity incidence (Table 4)}

Acute treatment toxicity information was available in 37 patients. Of these, 11 patients (30\%) experienced no adverse effects and 23 patients (62\%) experienced Grade 1-2 adverse effects, of which fatigue, nausea and pain were the most common. Only three patients $(8 \%)$ experienced Grade 3 acute toxicities (pain, fatigue and obstructive jaundice, respectively), which resolved quickly with clinical support. Late toxicity information was available for 32 patients, of whom 27 patients (84\%) reported no late adverse events. A total of six patients (19\%) experienced late adverse effects. One patient (3\%) was diagnosed with Grade 2 pancreatic insufficiency and one patient (3\%) experienced Grade 2 pain and nausea. Four 
Table 2 Patient, tumour and treatment characteristics ( $N=42$ patients)

\begin{tabular}{|c|c|c|}
\hline \multirow[t]{2}{*}{ Gender } & Male & $N=16(38.0 \%)$ \\
\hline & Female & $N=26(62.0 \%)$ \\
\hline \multirow[t]{4}{*}{ Tumour stage } & $\mathrm{T} 4$ & $N=37(88.1 \%)$ \\
\hline & T3 & $N=1(2.4 \%)$ \\
\hline & $\mathrm{T} 2$ & $N=3(7.1 \%)$ \\
\hline & $\mathrm{T} 1$ & $N=1(2.4 \%)$ \\
\hline \multirow[t]{3}{*}{ Site } & Head & $N=36(86.0 \%)$ \\
\hline & Body & $N=5(12.0 \%)$ \\
\hline & Tail & $N=1(2.0 \%)$ \\
\hline \multirow[t]{4}{*}{ PS (WHO) } & 0 & $N=2(5.0 \%)$ \\
\hline & 1 & $N=17(41.0 \%)$ \\
\hline & 2 & $N=22(52.0 \%)$ \\
\hline & 3 & $N=1(2.0 \%)$ \\
\hline \multirow{6}{*}{$\begin{array}{l}\text { Previous } \\
\text { treatment }\end{array}$} & None & $N=8(19.0 \%)$ \\
\hline & Chemotherapy only & $N=23(54.8 \%)$ \\
\hline & Chemoradiotherapy & $N=4(9.5 \%)$ \\
\hline & $\begin{array}{l}\text { Palliative surgery (gastric/biliary } \\
\text { bypass) + chemotherapy }\end{array}$ & $N=2(4.8 \%)$ \\
\hline & $\begin{array}{l}\text { Curative surgery (Whipples/ } \\
\text { Resection) + chemotherapy }\end{array}$ & $N=1(2.4 \%)$ \\
\hline & $\begin{array}{l}\text { Curative surgery (Whipples/ } \\
\text { Resection) + chemoradiotherapy }\end{array}$ & $N=4(9.5 \%)$ \\
\hline \multirow[t]{5}{*}{ SABR purpose } & PRIMARY & $N=8(19.0 \%)$ \\
\hline & (no other/prior treatment) & \\
\hline & $\begin{array}{l}\text { ADJUVANT } \\
\text { (within } 6 \text { months other } \\
\text { primary treatment) }\end{array}$ & $N=14(33.3 \%)$ \\
\hline & $\begin{array}{l}\text { CONSOLIDATION } \\
\text { (> } 6 \text { months post-primary } \\
\text { treatment to residual disease) }\end{array}$ & $N=11(26.2 \%)$ \\
\hline & $\begin{array}{l}\text { RETREAT } \\
\text { (> } 6 \text { months post-primary } \\
\text { treatment to disease relapse) }\end{array}$ & $N=9(21.4 \%)$ \\
\hline
\end{tabular}

patients suffered serious duodenal toxicities attributed to treatment: two patients developed Grade 4 duodenal strictures and two patients suffered Grade 4 gastro-intestinal GI haemorrhage. The patient who experienced Grade 2 pain and nausea also developed Grade 4 GI bleeding at 7 months post-treatment: however, the latter incidence was considered unrelated to treatment as it was concomitant with radiologically confirmed local tumour progression invading the duodenum.

\section{Association of SABR planning and delivery variables with toxicity incidence (Tables 5 and 6 )}

Treatment factors were examined in relation to posttreatment toxicity incidence (Table 5).
The number of fiducials statistically associated with incidence of acute toxicity $(p=0.002)$. A trend for uneven acute toxicity was observed with treatment purpose: relatively few patients who received only SABR experienced acute toxicity but patients who received SABR for palliative re-treatment of relapsed disease showed increased acute toxicity $(p=0.064)$. SABR variables that associated with late toxicity incidence were number of fiducials, treatment duration, treatment delivery time and percentage coverage (all $p<0.05$ ). For the two patients that experienced Grade 2 late toxicity, both had outlying delivery times (58 and 61 mins, respectively). Further, one patient had a very low outlying percentage coverage (79\%) and was treated with one implanted fiducial for on-treatment tracking.

Seven patients in total experienced Grade 3+ significant toxicities (Table 6). All three patients who experienced Grade 3 acute toxicities breached preferred duodenal constraints. Of the four patients who experienced late adverse treatment effects of Grade 4 GI bleeding or duodenal stricture, it was noted that all four had T4 tumours, none were planned with PET scan information, and all had outlying or sub-optimal treatment variables. Further, preferred duodenal OAR dose constraints were breached in three of the four patients. The first patient with duodenal toxicity was post-resection (distal pancreatectomy and splenectomy was performed the previous year), had received subsequent adjuvant chemotherapy and was re-treated with SABR with palliative intent for recurrent local disease. The surgery had left the patient with distorted anatomy, an unusually small PTV $(20.34 \mathrm{cc})$ and closely associated OAR. Although the duodenum was within the OAR constraint policy, only one implanted fiducial was possible for tumour tracking and the patient was prescribed treatment in three fractions over a longer treatment duration of 5 days because of anticipated toxicity risk. The second patient with duodenal toxicity also received SABR as a re-treatment with palliative intent for locally relapsed disease, also only had one implanted fiducial for tumour tracking, and was treated in 3 fractions over 5 days. Moreover, retrospective examination of the treatment plan showed that the duodenum was the key OAR, encircling and contacting the PTV more than $270^{\circ}$, and duodenal constraints were considerably exceeded. The third patient with duodenal toxicity received SABR as consolidation treatment for residual disease following chemotherapy $>6$ months prior. Their PTV was large $(109.3 \mathrm{cc})$ and although both prescription dose (22 Gy) and BED (38 Gy) were lower than average, preferred duodenal constraints were exceeded. The last patient with duodenal toxicity received SABR adjuvant to primary chemotherapy. The patient had a large PTV (104.5 cc) and again duodenal OAR constraints were exceeded. 
Table 3 SABR planning and delivery variables ( $N=42$ patients)

\begin{tabular}{|c|c|c|}
\hline \multirow[t]{5}{*}{ Number of fiducials } & 0 & $\mathrm{~N}=2(5.0 \%)^{*}$ \\
\hline & 1 & $N=8(19.0 \%)$ \\
\hline & 2 & $N=5(12.0 \%)$ \\
\hline & 3 & $N=21(50.0 \%)$ \\
\hline & 4 & $N=6(14.0 \%)$ \\
\hline \multirow[t]{4}{*}{ Treatment duration (days) } & 3 & $N=37(88.1 \%)$ \\
\hline & 4 & $N=1(2.4 \%)$ \\
\hline & 5 & $\mathrm{~N}=3(7.1 \%)$ \\
\hline & 7 & $N=1(2.4 \%)$ \\
\hline \multirow[t]{2}{*}{ PET scan data used for planning } & Yes & $N=11(26.0 \%)$ \\
\hline & No & $N=31(74.0 \%)$ \\
\hline PTV size (cc) & Mean $(95 \% \mathrm{Cl})$ & $76.25(63.83-88.67)$ \\
\hline Prescription dose (Gy) & Mean $(95 \% \mathrm{Cl})$ & $26.77(19.33-113.39)$ \\
\hline Prescription Isodose (\%) & Mean $(95 \% \mathrm{Cl})$ & $67.3(65.24-69.35)$ \\
\hline Percentage Cover (\%) & Mean $(95 \% \mathrm{Cl})$ & $96.6(95.52-97.66)$ \\
\hline Min dose to PTV (Gy) & Mean $(95 \% \mathrm{Cl})$ & $22.29(21.0-23.5)$ \\
\hline Max dose to PTV (Gy) & Mean $(95 \% \mathrm{Cl})$ & $40.2(38.5-41.9)$ \\
\hline Mean dose to PTV (Gy) & Mean $(95 \% \mathrm{Cl})$ & $31.5(30.8-32.3)$ \\
\hline Homogeneity Index (HI) & Mean $(95 \% \mathrm{Cl})$ & $1.5(1.45-1.55)$ \\
\hline BED (Gy) & Mean $(95 \% \mathrm{Cl})$ & $50.3(47.7-53.0)$ \\
\hline Fraction dose (Gy per fraction) & Mean $(95 \% \mathrm{Cl})$ & $8.9(8.6-9.2)$ \\
\hline Delivery time (mins) & Mean $(95 \% \mathrm{Cl})$ & $71.4(65.2-77.6)$ \\
\hline
\end{tabular}

*alternative planning and delivery strategy used for 2 patients

Table 4 Acute and late toxicity

\begin{tabular}{lcll}
\hline & Grade 1-2 & Grade 3 & Grade 4 \\
\hline Acute ( $\leq 3$ months post-treatment) toxicity & incidence in $N=37$ patients \\
NONE & $N=11(30 \%)$ & \\
Diarrhoea & $N=5(14 \%)$ & 0 & 0 \\
Nausea & $N=8(22 \%)$ & 0 & 0 \\
Vomiting & $N=2(5 \%)$ & 0 & 0 \\
Dyspepsia & $N=2(5 \%)$ & 0 & 0 \\
Anorexia & $N=2(5 \%)$ & 0 & 0 \\
Pain & $N=7(19 \%)$ & $N=1(3 \%)$ & 0 \\
Fatigue & $N=11(30 \%)$ & $N=1(3 \%)$ & 0 \\
Jaundice & $N=1(3 \%)$ & 0 & 0 \\
Obstructive Jaundice & 0 & $N=1(3 \%)$ & 0 \\
Late (> 3 months post-treatment) toxicity incidence in $N=32$ \\
NONE & $N=27(84 \%)$ & \\
Pain & $N=1(3 \%)^{*}$ & 0 & 0 \\
Nausea & $N=1(3 \%)^{*}$ & 0 & 0 \\
Pancreatic Insufficiency & $N=1(3 \%)$ & 0 & 0 \\
Gl Bleeding & 0 & 0 & $N=2(6 \%)$ \\
Duodenal Stricture & 0 & 0 & $N=2(6 \%)$ \\
\hline
\end{tabular}

*one patient experienced Grade 2 pain and Grade 2 nausea
Survival outcomes (Fig. 1) and association with planning and delivery variables

Post-treatment follow-up information was available for $39 / 42(93 \%)$ patients. Two patients $(5 \%)$ converted to resectable status post-treatment: one subsequently underwent complete resection but unfortunately the other was medically unfit for operation. Overall, 15 (36\%) patients died with distant progression and no local failure, and two patients (5\%) died with local failure and no distant progression. Kaplan-Meier survival analysis showed median FFLP, PFS and OS were 9.8, 5.9 and 8.4 months, respectively. Actuarial 1 year survivor function (95\% C.I) for FFLP, PFS and OS were 43.4 (20.8, 64.2)\%, 19.8 (7.8, $35.9) \%$, and 39.0 (22.7, 55.0)\%, respectively. Survival plots illustrating FFLP and OS are shown in Fig. 1. Log-rank analysis to test the equality of the KaplanMeier survivor function across treatment variables, split by their medians, on FFLP and OS showed no statistical differences. Treatment purpose was also investigated by log-rank analysis, where patients who received SABR > 6 months post-primary therapy as consolidation or re-treat for residual or relapsed disease were compared to patients who received SABR as primary or adjuvant therapy: importantly they showed similar FFLP and OS, indicating SABR may be extending survival outcomes for residual or relapsed disease. When multi-variate Cox proportional hazard regression modelling (adjusted for all treatment variables) was applied to examine the influence of continuous or dichotomous treatment variables on FFLP and OS, both PTV size (cc) and treatment duration (days) significantly associated with OS $(p<0.05)$.

\section{LQ radiobiological modelling: Comparison of calculated parameters (Table 7)}

The BED calculated for the reference conventional conformal radiotherapy schedule $(50.4$ Gy in 28 fractions delivered in 37 days) was $40.5 \mathrm{~Gy}_{10}$. However, as conformal, conventionally fractionated RT is delivered to the minimum 95\% isodose within the PTV $[45,46]$, the minimum dose to the PTV would be 47.88 Gy with the comparator regimen, which equates to a minimum BED of $37.1 \mathrm{~Gy}_{10}$. For the normal tissues, the comparator regimen delivers a minimum BED of $75.2 \mathrm{~Gy}_{3}$. Using the LQ model, the estimated SABR equivalent to the comparator schedule is $3 \times 7.45 \mathrm{~Gy}$, giving a total dose of 22.35 Gy and associated normal tissue BED of $77.85 \mathrm{~Gy}_{3}$. For patients in this study who received prescribed dose to optimal individualized isodose (mean $=67.3 \%)$, only $21 / 42(50 \%)$ of patients received a minimum PTV dose of $22.35 \mathrm{~Gy}$.

\section{Discussion}

This study was the first to use LQ modelling to assess pancreatic SABR efficacy and to comprehensively 
Table 5 Association of treatment factors and treatment toxicity

\begin{tabular}{|c|c|c|c|c|c|c|c|c|}
\hline & \multicolumn{4}{|c|}{ Acute toxicity max grade $(n=37)$} & \multicolumn{4}{|c|}{ Late toxicity max grade $(n=32)$} \\
\hline & 0 & $1-2$ & 3 & $p$-value & 0 & 2 & 4 & p-value \\
\hline \multicolumn{9}{|l|}{ Number of fiducialst } \\
\hline $0-1$ & 1 & 6 & 0 & $0.0002^{*}$ & 4 & 1 & 2 & $0.01^{*}$ \\
\hline $2-4$ & 10 & 17 & 3 & & 22 & 1 & 2 & \\
\hline \multicolumn{9}{|l|}{ Treatment days $†$} \\
\hline 3 & 11 & 20 & 3 & 0.37 & 25 & 2 & 2 & $0.012^{*}$ \\
\hline $4-7$ & 0 & 3 & 0 & & 1 & 0 & 2 & \\
\hline \multicolumn{9}{|l|}{ Previous surgery† } \\
\hline Yes & 1 & 5 & 0 & 0.47 & 4 & 0 & 1 & 0.68 \\
\hline No & 10 & 18 & 3 & & 22 & 2 & 3 & \\
\hline \multicolumn{9}{|l|}{ Previous irradiationt } \\
\hline Yes & 0 & 7 & 1 & 0.11 & 6 & 0 & 0 & 0.43 \\
\hline No & 11 & 16 & 2 & & 20 & 2 & 4 & \\
\hline \multicolumn{9}{|l|}{ Min dose to PTV† } \\
\hline$<22.35 G y$ & 5 & 10 & 2 & 0.75 & 9 & 2 & 2 & 0.17 \\
\hline$\geq 22.35 G y$ & 6 & 11 & 1 & & 17 & 0 & 2 & \\
\hline \multicolumn{9}{|l|}{ SABR purposet } \\
\hline Sole primary & 1 & 6 & 0 & 0.064 & 6 & 1 & 0 & 0.62 \\
\hline Adjuvant & 6 & 4 & 1 & & 7 & 0 & 1 & \\
\hline Consolidation & 4 & 6 & 1 & & 8 & 1 & 1 & \\
\hline Retreat & 0 & 5 & 2 & & 5 & 0 & 2 & \\
\hline Treatment time (mins) & 77.5 & 69.9 & 68.3 & 0.570 & 67.7 & 59.5 & 83.0 & $0.045^{*}$ \\
\hline PTV $(c c) \neq$ & 93.5 & 72.1 & 67.9 & 0.355 & 77.2 & 61.5 & 79.3 & 0.875 \\
\hline PTV min dose (cGy) $\ddagger$ & 2342.6 & 2227.6 & 2115.8 & 0.605 & 2317.7 & 1901.5 & 2332.4 & 0.396 \\
\hline PTV max dose (cGy) $\neq$ & 3951.3 & 3974.7 & 4149.2 & 0.8819 & 4120.6 & 3920.5 & 3861.9 & 0.622 \\
\hline PTV mean dose $(\mathrm{cGy}) \neq$ & 3151.9 & 3118.0 & 3241.9 & 0.879 & 3225.4 & 3085.6 & 3015.0 & 0.493 \\
\hline Prescription dose (cGy) $\neq$ & 2736.4 & 2647.8 & 2700.0 & 0.735 & 2740.4 & 2700.0 & 2612.5 & 0.7067 \\
\hline Prescription isodose $(\%) \neq$ & 69.6 & 67.5 & 65.3 & 0.554 & 67.0 & 69.0 & 68.3 & 0.882 \\
\hline Percentage cover $(\%) \neq$ & 96.1 & 97.0 & 97.3 & 0.771 & 97.1 & 88.1 & 91.1 & $0.002^{*}$ \\
\hline BED (Gy10) ₹ & 52.3 & 49.2 & 52.0 & 0.650 & 52.1 & 51.0 & 49.0 & 0.811 \\
\hline $\mathrm{HI} \neq$ & 1.44 & 1.50 & 1.54 & 0.523 & 1.51 & 1.46 & 1.47 & 0.833 \\
\hline
\end{tabular}

*Statistically significant at $0.05 \%$ level + Numbers are frequencies, tested for association using Chi-squared test; $\neq$ Numbers are means, tested for association using ANOVA

examine the influence of patient and planning factors on toxicity and outcome. The study was conducted in a 'real-world' patient series, which is crucial for understanding treatment effectiveness and safety in everyday clinical practice. Our results support SABR as an encouraging modality for locally inoperable pancreatic cancer, with particular benefits as a re-treatment, consolidation or salvage boost, or as an alternative treatment for patients with poor PS or co-morbidity. Although toxicity was low and survival was better than expected - especially considering nearly half of patients were treated more than 6-months after primary treatment - both FFLP survival analysis and LQ modelling showed scope to improve local control through dose escalation. The few serious incidences of late duodenal toxicity indicate that this would need to be approached cautiously with increased stringency on duodenal protection through highly detailed individualised planning.

Low toxicity was obtained that was better than many other SABR studies [20-22, 25, 28, 36], despite larger PTVs and higher prescription doses in this study. This indicates planning methods and on-treatment dynamic targeting with Synchrony ${ }^{\circ}$ were generally good and consistent with other studies [20, 25, 27-30, 32, 34, 36]. The main limitation when examining patient and treatment factors in relation to toxicity was the low incidence of 
Table 6 Duodenal dosimetry and treatment factors for patients with Grade 3+ toxicity

\begin{tabular}{|c|c|c|c|c|c|c|c|c|c|c|}
\hline \multirow{2}{*}{$\begin{array}{l}\text { Grade 3+ } \\
\text { Toxicity }\end{array}$} & \multicolumn{4}{|c|}{ Treatment Factors } & \multicolumn{6}{|c|}{ Duodenal Dosimetry } \\
\hline & Fids & PTV & Prescribed Dose & Dur'n & D0.035 cc & D1.0 cc & D5.0 cc & D10.0 cc & V15 Gy & V20 Gy \\
\hline \multicolumn{11}{|l|}{ ACUTE } \\
\hline Grade 3 pain & 4 & 39.84 cc & 30.0 Gy 3 fractions & 3 days & $33.9 \mathrm{~Gy}^{*}$ & 25.4 Gy & $15.8 \mathrm{~Gy}$ & $12.8 \mathrm{~Gy}^{*}$ & $5.9 \mathrm{cc}$ & $2.5 \mathrm{cc}$ \\
\hline Grade 3 fatigue & 3 & $44.22 c c$ & 30.0 Gy 3 fractions & 3 days & $34.9 \mathrm{~Gy}^{*}$ & $27.9 \mathrm{~Gy}$ & $20.5 \mathrm{~Gy}^{*}$ & $16.2 \mathrm{~Gy}^{*}$ & $12.3 c c$ & $5.4 c c$ \\
\hline Grade 3 obstructive jaundice & 4 & 119.57 cc & 21.0 Gy 3 fractions & 3 days & $23.8 \mathrm{~Gy}^{*}$ & $22.6 \mathrm{~Gy}$ & $21.1 \mathrm{~Gy}^{*}$ & $19.6 \mathrm{~Gy}^{*}$ & $32.2 \mathrm{cc}$ & $8.6 c c$ \\
\hline \multicolumn{11}{|l|}{ LATE } \\
\hline Grade 4 duodenal stricture & $1^{\dagger}$ & $20.34 c c$ & 28.5 Gy 3 fractions & 5 days & $11.2 \mathrm{~Gy}$ & $8.3 \mathrm{~Gy}$ & $6.8 \mathrm{~Gy}$ & $6.2 \mathrm{~Gy}$ & $0.0 \mathrm{cc}$ & $0.0 c c$ \\
\hline Grade 4 Gl bleed & $1^{\dagger}$ & $83.49 \mathrm{cc}$ & 27.0 Gy 3 fractions & 5 days & $29.3 \mathrm{~Gy}^{*}$ & $28.3 \mathrm{~Gy}$ & $26.2 \mathrm{~Gy}^{*}$ & $23.9 \mathrm{~Gy}^{*}$ & $39.1 c c$ & $19.4 c c$ \\
\hline Grade 4 Gl bleed & 3 & $109.31 \mathrm{cc}$ & 22.0 Gy 3 fractions & 3 days & $24.2 \mathrm{~Gy}^{*}$ & 23.2 Gy & $22.5 \mathrm{~Gy}^{*}$ & $21.8 \mathrm{~Gy}^{*}$ & $63.3 c c$ & $24.3 \mathrm{cc}$ \\
\hline Grade 4 duodenal stricture & 3 & $104.25 \mathrm{cc}$ & 27.0 Gy 3 fractions & 3 days & $31.6 \mathrm{~Gy}^{*}$ & $29.1 \mathrm{~Gy}$ & $26.0 \mathrm{~Gy}^{*}$ & $21.8 \mathrm{~Gy}^{*}$ & $24.2 c c$ & $12.8 c c$ \\
\hline
\end{tabular}

*Duodenal planning dosimetry exceeded institution preferred 3 fraction constraints. $\dagger$ single fiducial conferring anticipated increased risk of duodenal complications [47]

late and Grade 3+ toxicity events: multiple testing is acknowledged as an additional limitation. The only factors that showed association with acute toxicity were number of fiducials $(p=0.0002)$ and treatment purpose $(p=$ $0.064)$. The former aligns with our previous dose-volume histogram study of duodenal risk in an overlapping cohort of pancreatic SABR patients that showed increased toxicity risk for patients with single or no fiducial [47]. The latter is probably due to the patients who were re-treated who had one or more sub-optimal treatment factors (unusually large or small PTV and/or tightly adjacent OAR and/or only one fiducial and/or breached OAR constraints) and thus a higher risk of treatment toxicity was expected. Number of fiducials also associated with late toxicity [47]. Other variables that associated with late toxicity were increased treatment duration period ( $>3$ days), treatment delivery time (mins), and coverage: (\%): however, we consider these factors to be associative rather than causal for late toxicity for several reasons. First, the main reason for serious duodenal toxicity in three patients was breached duodenal OAR constraints. Second, the uneven distribution noted for treatment delivery time and late treatment toxicities is mainly because two patients who showed Grade 2 late treatment toxicities had lower than average treatment times. Third, the association between treatment duration and percentage coverage likely reflects purposeful selection of these parameters because of recognised increased duodenal toxicity risk due to individual medical, anatomical planning and delivery challenges. For example, SABR is known to be least successful when the treatment volume is large and the 'dose-cloud' is not tightly conformal, and to be sub-optimal when fewer fiducials are used compromising the accuracy of dynamic tumour tracking. As such, it is notable that of the four patients that suffered duodenal toxicity, two had large PTV (> $100 \mathrm{cc}$ ), and the other two (who were treated palliatively $>6$ months after primary therapy for recurrent disease) had only one fiducial implanted for on-treatment tumour tracking and were purposefully prescribed treatment over 5 days because of anticipated toxicity risk. Moreover, three of the patients who suffered duodenal toxicity breached the preferred duodenal OAR dose constraints, with the volume of duodenum receiving > 15 Gy considerably exceeding limits correlated with duodenal toxicity [36]. Increased vigilance and stringency to duodenal dose constraints, particularly for patients with large PTV, distorted anatomy, closely adjacent OAR, or fewer fiducials, is therefore appropriate. Indeed, our recent dose-volume histogram duodenal risk map study of duodenal risk in an overlapping cohort of pancreatic SABR patients showed a $10 \%$ risk level for Grade 3-4 duodenal haemorrhage or stricture when D1 cc = D31.4 Gy [47]. Furthermore, we found that the use of multiple fiducials showed one-fifth of the risk for Grade 3-4 duodenal complications compared with single fiducial or Xsight ${ }^{\circ}$ Spine tumour tracking. As such, we advocate implanting at least four fiducials and using three or more stable fiducials for optimal tumour tracking during treatment delivery and, based on estimated 10\% duodenal risk levels, now impose the stringent duodenal constraint of D1.0 cc $<$ 31.4 Gy for all pancreatic patients treated with $\leq 30$ Gy in three fractions. Concomitantly, in response to collective experience, we have revised our duodenal D0.035 cc constraint to the higher limit of 24 Gy [47]. It is additionally noted that the incorporation of more extensive measures for duodenal assessment during individualised planning/ schedules, such as Lyman modelling for normal tissue complication probability [36], late complications [44] or Red Shell volume calculation [48] may also be helpful in the prevention of duodenal toxicity.

As all patients were inoperable and non-metastatic, they would be expected to have similar prognostic outcomes to intermediate stage patients and may reasonably be compared with similar intermediate stage cohorts in the literature. Overall survival following SABR was good 

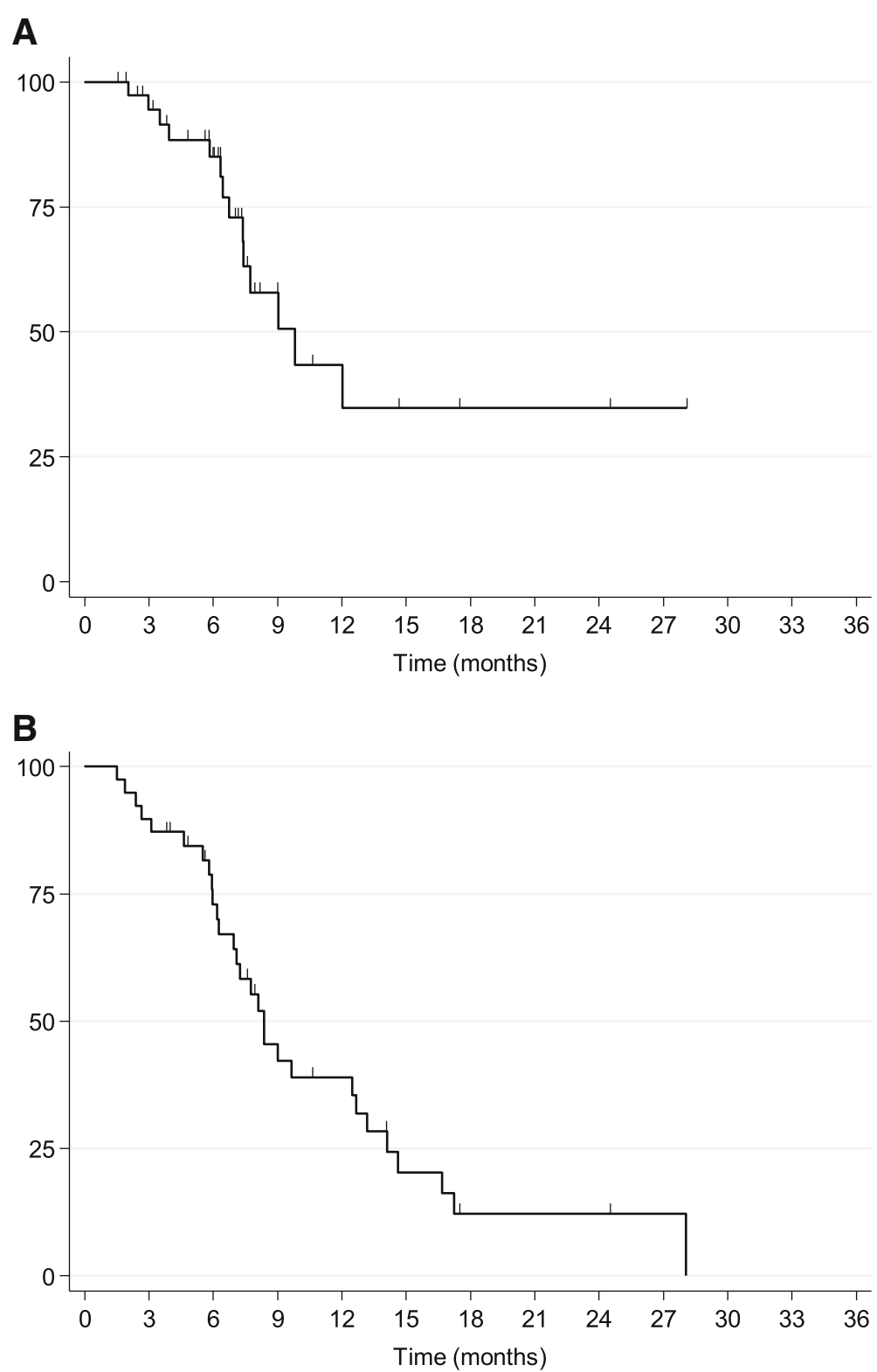

Fig. 1 Kaplan-Meier survival plots illustrating a) percentage (\%) freedom-from-local-progression (FFLP) in months and b) percentage (\%) overall survival (OS) in months

Table 7 Radiobiological (LQ) modelling: calculated comparator regimen and SABR equivalent parameters

\begin{tabular}{|c|c|c|c|c|c|c|}
\hline & $\begin{array}{l}\text { Total Dose } \\
\text { (D) }\end{array}$ & Fraction Dose $(d)$ & $\begin{array}{l}\text { Fractions } \\
\text { (n) }\end{array}$ & $\begin{array}{l}\text { Duration } \\
\text { (days) }\end{array}$ & $\begin{array}{l}\text { BED } \\
\left(\mathrm{Gy}_{10}\right)\end{array}$ & $\begin{array}{l}\mathrm{BED} \\
\left(\mathrm{G} y_{3}\right)\end{array}$ \\
\hline $\begin{array}{l}\text { Comparator regimen } \\
\text { (100\% dose to PTV) }\end{array}$ & 50.4 Gy & $1.8 \mathrm{~Gy}$ & 28 & 37 & 40.5 Gy & 80.6 Gy \\
\hline \multirow[t]{2}{*}{ SABR equivalent } & $23.55 \mathrm{~Gy}$ & 7.85 Gy & 3 & 3 & $40.5 \mathrm{~Gy}$ & $77.0 \mathrm{~Gy}$ \\
\hline & \multicolumn{6}{|c|}{ Number of patients treated with total dose $\geq 23.55 \mathrm{~Gy}=39 / 42(92.9 \%)$} \\
\hline $\begin{array}{l}\text { Comparator regimen } \\
\text { (min 95\% dose to PTV) }\end{array}$ & $47.88 \mathrm{~Gy}$ & $1.71 \mathrm{~Gy}$ & 28 & 37 & 37.5 Gy & $75.27 \mathrm{~Gy}$ \\
\hline \multirow[t]{2}{*}{ SABR equivalent } & $22.35 \mathrm{~Gy}$ & 7.45 Gy & 3 & 3 & $37.5 \mathrm{~Gy}$ & 77.85 Gy \\
\hline & \multicolumn{6}{|c|}{ Number of patients treated with minimum PTV dose $\geq 22.35 \mathrm{~Gy}=21 / 42(50 \%)$} \\
\hline
\end{tabular}


considering that $48 \%$ of patients were treated $>6$ months after primary therapy, indicating that SABR may be extending survival times for patients with residual or relapsed local disease. The median OS of 8.4 months is comparable to that of first line chemoradiotherapy treatments in randomised LAPC trials $[9,10,49]$ and the actuarial 1 year OS of $39 \%$ is comparable [29-31,33] or better than $[21,22,25,32]$ other studies of SABR in LAPC. However, the FFLP of $43 \%$ at 1 year is lower in comparison to other SABR studies [20-22, 25-35], where some achieved FFLP rates of $70-94 \%$ at 1 year $[22,25,29,32]$. Although the low FFLP rate is likely to have been negatively influenced by the fact that almost half of patients were treated $>6$ months after primary therapy to residual or relapsed disease, it also suggests that higher rates of local control may be achievable with SABR. The lack of any association of treatment factors with FFLP in log-rank or multi-variate analysis indicates that neither current planning or delivery methods are contributing to local failure. Both PTV size and treatment course duration (days) associated with OS. The relationship between size and OS is not clear and may be related to disease advance, and the association with treatment days likely reflects purposeful selection of a longer treatment course for re-treat/palliative/relapse patients with more advanced disease and worse PS.

Although there are limitations to LQ modelling when extrapolating from schedules involving conventional fraction sizes to those involving larger fractions, the results indicated that $50 \%$ of the patients treated received a minimum PTV dose that was less potent than a comparator standard conformal radiotherapy regimen. The main reason was because prescribed SABR dose was delivered to a patient individualised isodose line to balance target volume coverage with adjacent OAR risk, whereas conformal RT is delivered to the minimum 95\% isodose within the PTV. It is additionally notable that the reference schedule of 50.4 Gy in 28 fractions over 5.5 weeks is associated with a tumor BED of $\sim 40.5$ Gy. This is considered likely to eradicate only the smallest tumour of moderate radiosensitivity, whereas pancreatic tumours are typically moderately sized and relatively radioresistant. Recent analysis of clinical radiation dose response in pancreatic cancer using LQ modelling has indicated that a BED of $\sim 40.5$ Gy may achieve $>50 \%$ local control [18]. A BED $>70$ Gy was calculated to achieve significant tumour response (size reduction consistent with complete or partial response) and thus a schedule of three fractions, each delivering 9.2 Gy, was proposed accordingly for SABR [18]. Recent studies have provided support for the feasibility, similar toxicity and potential increased local control with escalated dose [50]. In our study, the lack of association of toxicity with maximum dose to PTV or prescription dose indicates that a higher overall dose is unlikely to affect toxicity if measures to limit duodenal dose are emphasized. Together these data indicate need and scope to escalate SABR doses to achieve minimum PTV doses $>22.5$ Gy and optimal BED $>70$ Gy for improved efficacy. Our revised duodenal D0.035 dose constraint to the higher value of 24 Gy will allow greater scope for dose escalation. The recent adoption of 5-6 fraction SABR regimens are additionally anticipated to improve toxicity profiles. However, given the ongoing risk for serious duodenal toxicity in a proportion of patients, dose escalation would need to be implemented with great care and awareness of risk for individual patients.

\section{Conclusions}

CyberKnife ${ }^{\bullet}$ treatment was well tolerated and survival in the cohort was encouraging, supporting SABR as a good treatment option in the primary, adjuvant or re-treatment setting. The LQ modelling results and relatively low FFLP indicate scope for dose escalation to improve local control and survival. However, to avoid serious duodenal toxicity a cautious approach needs to be taken, incorporating careful assessment of individual patients for dose escalation suitability and concomitant enhanced stringency on duodenal protection.

\section{Abbreviations \\ ${ }^{18}$ F-FDG-PET: 18-fluorodeoxyglucose positron emission tomography; BED: Biological effective dose; Cl: Confidence interval; CT: Computed tomography; EUS: Endoscopic ultrasound; FFLP: Freedom-from-local- progression; Gl: Gastro-intestinal; GTV: Gross target volume; HI: Homogeneity index; ITV: Internal target volume; LAPC: Locally advanced pancreatic cancer; LQ: Linear-quadratic; OAR: Organs-at-risk; OS: Overall survival; PFS: Progression-free-survival; PS: Performance status; PTV: Planning target volume; SABR: Stereotactic ablative radiotherapy; XSS: XSight Spine}

\section{Acknowledgements}

Preliminary results of this study were previously presented in Abstract form at the SRS/SBRT Scientific Meeting February 2013, CA, USA. The support of radiographers, medical physicists, dosimetrists and radiation oncologists at The Harley Street Clinic Radiotherapy Department is appreciated for their contributions to the success of treatment and helpful technical discussions. Tim Cross and Gillian Santorelli are gratefully acknowledged for careful data management and efficient statistical analysis, respectively.

\section{Funding}

No specific funding source was used for this study as it was carried out as part of research and development within the auspices of HCA International at the CyberKnife Centre, The Harley Street Clinic.

\section{Availability of data and materials}

The patient datasets are the property of HCA International. A patient-anonymised dataset is available from the corresponding author on reasonable request.

\section{Authors' contributions}

CG data acquisition and interpretation, critical revision of manuscript and final approval. NP study conception, data interpretation and manuscript final approval. MG data analysis and interpretation, manuscript preparation and critical revision. RD data analysis and interpretation and final manuscript approval. PP study conception, design and management, data interpretation and manuscript approval. All authors read and approved the final manuscript. 


\section{Ethics approval and consent to participate}

This study was carried out as part of research and development within the auspices of HCA International at the CyberKnife Centre, The Harley Street Clinic. Patient consent to participate was not applicable as the study was carried out as an anonymised retrospective review of treatment: all patient identifiers were removed for data analysis and publication purposes.

\section{Consent for publication}

Not applicable.

\section{Competing interests}

The authors declare that they have no competing interests.

\section{Publisher's Note}

Springer Nature remains neutral with regard to jurisdictional claims in published maps and institutional affiliations.

\section{Author details}

'Guys and St Thomas' NHS Foundation Trust, London, UK. ${ }^{2}$ The London CyberKnife Centre, The Harley Street Clinic, 81 Harley Street, London W1G 8PP, UK. ${ }^{3}$ St. Bartholomew's Hospital, London, UK. ${ }^{4}$ Department of Surgery and Cancer, Imperial College London, London, UK.

Received: 11 June 2018 Accepted: 24 September 2018 Published online: 19 October 2018

\section{References}

1. Carrato A, Falcone A, Ducreux M, Valle JW, Parnaby A, Djazouli K, et al. A systematic review of the burden of pancreatic cancer in Europe: real-world impact on survival, quality of life and costs. J Gastrointest Cancer. 2015;46: 201-11.

2. Siegel R, Naishadham D, Jemal A. Cancer statistics, 2013. CA Cancer J Clin. 2013;63:11-30

3. Cancer Research UK. Pancreatic Cancer statistics 2018. https://www. cancerresearchuk.org/health-professional/cancer-statistics/statistics-bycancer-type/pancreatic-cancer. Accessed 06 Sept 2018.

4. Hidalgo M. Pancreatic cancer. N Engl J Med. 2010;362:1605-17.

5. Wagner M, Redaelli C, Lietz M, Seiler CA, Friess H, Buchler MW. Curative resection is the single most important factor determining outcome in patients with pancreatic adenocarcinoma. Br J Surg. 2004;91:586-94.

6. Morganti AG, Massaccesi M, La Torre G, Caravatta L, Piscopo A, Tambaro R, et al. A systematic review of resectability and survival after concurrent chemoradiation in primarily unresectable pancreatic cancer. Ann Surg Oncol. 2010;17:194-205.

7. Truty MJ, Thomas RM, Katz MH, Vauthey JN, Crane C, Varadhachary GR, et al. Multimodality therapy offers a chance for cure in patients with pancreatic adenocarcinoma deemed unresectable at first operative exploration. J Am Coll Surg. 2012;215:41-51 discussion -2.

8. Crane CH, Varadhachary GR, Yordy JS, Staerkel GA, Javle MM, Safran H, et al. Phase II trial of cetuximab, gemcitabine, and oxaliplatin followed by chemoradiation with cetuximab for locally advanced (T4) pancreatic adenocarcinoma: correlation of Smad4(Dpc4) immunostaining with pattern of disease progression. J Clin Oncol. 2011;29:3037-43.

9. Johung K, Saif MW, Chang BW. Treatment of locally advanced pancreatic cancer: the role of radiation therapy. Int J Radiat Oncol Biol Phys. 2012;82: 508-18.

10. Sultana A, Tudur Smith C, Cunningham D, Starling N, Tait D, Neoptolemos $J P$, et al. Systematic review, including meta-analyses, on the management of locally advanced pancreatic cancer using radiation/combined modality therapy. Br J Cancer. 2007;96:1183-90.

11. lacobuzio-Donahue CA, Fu B, Yachida S, Luo M, Abe H, Henderson CM, et al. DPC4 gene status of the primary carcinoma correlates with patterns of failure in patients with pancreatic cancer. J Clin Oncol. 2009;27:1806-13.

12. Ben-Josef E, Schipper M, Francis IR, Hadley S, Ten-Haken R, Lawrence T, et al. A phase I/II trial of intensity modulated radiation (IMRT) dose escalation with concurrent fixed-dose rate gemcitabine (FDR-G) in patients with unresectable pancreatic cancer. Int J Radiat Oncol Biol Phys. 2012;84: 1166-71.

13. Chang JS, Wang ML, Koom WS, Yoon Hl, Chung Y, Song SY, et al. High-dose helical tomotherapy with concurrent full-dose chemotherapy for locally advanced pancreatic cancer. Int J Radiat Oncol Biol Phys. 2012;83:1448-54.
14. Loehrer PJ Sr, Feng Y, Cardenes H, Wagner L, Brell JM, Cella D, et al. Gemcitabine alone versus gemcitabine plus radiotherapy in patients with locally advanced pancreatic cancer: an eastern cooperative oncology group trial. J Clin Oncol. 2011;29:4105-12

15. Murphy JD, Adusumilli S, Griffith KA, Ray ME, Zalupski MM, Lawrence TS, et al. Full-dose gemcitabine and concurrent radiotherapy for unresectable pancreatic cancer. Int J Radiat Oncol Biol Phys. 2007;68:801-8.

16. Hammel P, Huguet F, van Laethem $J$, Goldstein D, Glimelius B, Artru P, et al. Effect of chemoradiotherapy vs chemotherapy on survival in patients with locally advanced pancreatic cancer controlled after 4 months of gemcitabine with or without erlotinib: the LAP07 randomized clinical trial. JAMA. 2016;315:1844-53.

17. Krishnan S, Rana $V$, Janjan NA, Varadhachary GR, Abbruzzese $J$, Das $P$, et al. Induction chemotherapy selects patients with locally advanced, unresectable pancreatic cancer for optimal benefit from consolidative chemoradiation therapy. Cancer. 2007;110:47-55.

18. Moraru IC, Tai A, Erickson B, Li XA. Radiation dose responses for chemoradiation therapy of pancreatic cancer: an analysis of compiled clinical data using biophysical models. Pract Radiat Oncol. 2014;4:13-9.

19. Chauffert B, Mornex F, Bonnetain F, Rougier P, Mariette C, Bouche O, et al. Phase III trial comparing intensive induction chemoradiotherapy (60 Gy, infusional 5-FU and intermittent cisplatin) followed by maintenance gemcitabine with gemcitabine alone for locally advanced unresectable pancreatic cancer. Definitive results of the 2000-01 FFCD/SFRO study. Ann Oncol. 2008;19:1592-9.

20. Goyal K, Einstein D, Ibarra RA, Yao M, Kunos C, Ellis R, et al. Stereotactic body radiation therapy for nonresectable tumors of the pancreas. I Surg Res. 2012;174:319-25.

21. Hoyer M, Roed H, Sengelov L, Traberg A, Ohlhuis L, Pedersen J, et al. PhaseIl study on stereotactic radiotherapy of locally advanced pancreatic carcinoma. Radiother Oncol. 2005;76:48-53.

22. Koong AC, Christofferson E, Le Q-T, Goodman KA, Ho A, Kuo T, et al. Phase II study to assess the efficacy of conventionally fractionated radiotherapy followed by a stereotactic radiosurgery boost in patients with locally advanced pancreatic cancer. Int J Radiat Oncol Biol Phys. 2005;63:320-3.

23. Chang BK, Timmerman RD. Stereotactic body radiation therapy: a comprehensive review. Am J Clin Oncol. 2007;30:637-44.

24. Martin A, Gaya A. Stereotactic body radiotherapy: a review. Clin Oncol (R Coll Radiol). 2010;22:157-72.

25. Chang DT, Schellenberg D, Shen J, Kim J, Goodman KA, Fisher GA, et al. Stereotactic radiotherapy for unresectable adenocarcinoma of the pancreas. Cancer. 2009;115:665-72.

26. Chuong MD, Springett GM, Freilich JM, Park CK, Weber JM, Mellon EA, et al. Stereotactic body radiation therapy for locally advanced and borderline resectable pancreatic cancer is effective and well tolerated. Int J Radiat Oncol Biol Phys. 2013;86:516-22.

27. Koong AC, Le QT, Ho A, Fong B, Fisher G, Cho C, et al. Phase I study of stereotactic radiosurgery in patients with locally advanced pancreatic cancer. Int J Radiat Oncol Biol Phys. 2004;58:1017-21.

28. Mahadevan A, Jain S, Goldstein M, Miksad R, Pleskow D, Sawhney M, et al. Stereotactic body radiotherapy and gemcitabine for locally advanced pancreatic cancer. Int J Radiat Oncol Biol Phys. 2010;78:735-42.

29. Mahadevan A, Miksad R, Goldstein M, Sullivan R, Bullock A, Buchbinder E, et al. Induction gemcitabine and stereotactic body radiotherapy for locally advanced nonmetastatic pancreas cancer. Int J Radiat Oncol Biol Phys. 2011; 81:e615-e22.

30. Schellenberg D, Goodman KA, Lee F, Chang S, Kuo T, Ford JM, et al. Gemcitabine chemotherapy and single-fraction stereotactic body radiotherapy for locally advanced pancreatic cancer. Int J Radiat Oncol Biol Phys. 2008;72:678-86.

31. Schellenberg D, Kim J, Christman-Skieller C, Chun CL, Columbo LA, Ford JM, et al. Single-fraction stereotactic body radiation therapy and sequential gemcitabine for the treatment of locally advanced pancreatic cancer. Int J Radiat Oncol Biol Phys. 2011;81:181-8.

32. Lominska C, Unger K, Nasr N, Haddad N, Gagnon G. Stereotactic body radiation therapy for reirradiation of localized adenocarcinoma of the pancreas. Radiat Oncol. 2012;7:74.

33. Tozzi A, Comito T, Alongi F, Navarria P, Iftode C, Mancosu P, et al. SBRT in unresectable advanced pancreatic cancer: preliminary results of a monoinstitutional experience. Radiat Oncol. 2013;8:148. 
34. Gurka M, Collins S, Slack R, Tse G, Charabaty A, Ley L, et al. Stereotactic body radiation therapy with concurrent full-dose gemcitabine for locally advanced pancreatic cancer: a pilot trial demonstrating safety. Radiat Oncol. 2013:8:44.

35. Seo Y, Kim M-S, Yoo S, Cho C, Yang K, Yoo H, et al. Stereotactic body radiation therapy boost in locally advanced pancreatic cancer. Int J Radiat Oncol Biol Phys. 2009;75:1456-61.

36. Murphy JD, Christman-Skieller C, Kim J, Dieterich S, Chang DT, Koong AC. A dosimetric model of duodenal toxicity after stereotactic body radiotherapy for pancreatic cancer. Int J Radiat Oncol Biol Phys. 2010;78:1420-6.

37. Su T-S, Liang P, Lu H-Z, Liang J-N, Liu J-M, Zhou Y, et al. Stereotactic body radiotherapy using Cyberknife for locally advanced unresectable and metastatic pancreatic cancer. World J Gastroenterol. 2015;21:8156-62.

38. Zhong J, Patel K, Switchenko J, Cassidy RJ, Hall WA, Gillespie T, et al. Outcomes for patients with locally advanced pancreatic adenocarcinoma treated with stereotactic body radiation therapy versus conventionally fractionated radiation. Cancer. 2017;123:3486-93.

39. Lo SS, Sahgal A, Chang EL, Mayr NA, Teh BS, Huang Z, et al. Serious complications associated with stereotactic ablative radiotherapy and strategies to mitigate the risk. Clin Oncol (R Coll Radiol). 2013;25:378-87.

40. Dieterich S, Gibbs IC. The CyberKnife in clinical use: current roles, future expectations. Front Radiat Ther Oncol. 2011;43:181-94.

41. Benedict SH, Yenice KM, Followill D, Galvin JM, Hinson W, Kavanagh B, et al. Stereotactic body radiation therapy: the report of AAPM task group 101. Med Phys. 2010;37:4078-101.

42. Timmerman RD. An overview of hypofractionation and introduction to this issue of seminars in radiation oncology. Semin Radiat Oncol. 2008;18:215-22.

43. Fowler JF. The linear-quadratic formula and progress in fractionated radiotherapy. Br J Radiol. 1989;62:679-94.

44. Fowler JF. 21 years of biologically effective dose. Br J Radiol. 2010;83:554-68.

45. ICRU Report 50. Prescribing, Recording and Reporting Photon Beam Therapy. Bethesda: International Commission on Radiation Units and Measurements; 1994

46. ICRU Report 62. Prescribing, Recording and Reporting Photon Beam Therapy. Bethesda: International Commission on Radiation Units and Measurements; 1999

47. Goldsmith C, Price P, Cross T, Loughlin S, Cowley I, Plowman N. Dosevolume histogram analysis of stereotactic body radiotherapy treatment of pancreatic cancer: a focus on duodenal dose constraints. Semin Radiat Oncol. 2016;26:149-56.

48. Yang J, Fowler JF, Lamond JP, Lanciano R, Feng J, Brady LW. Red shell: defining a high-risk zone of normal tissue damage in stereotactic body radiation therapy. Int J Radiat Oncol Biol Phys. 2010;77:903-9.

49. Crane $\mathrm{CH}$, Varadhachary $\mathrm{G}$, Settle $\mathrm{SH}$, Fleming JB, Evans DB, Wolff RA. The integration of chemoradiation in the care of patient with localized pancreatic cancer. Cancer Radiother. 2009;13:123-43.

50. Rudra S, Jiang N, Rosenberg SA, Olsen JR, Parikh PJ, Bassetti MF, et al. High dose adaptive MRI guided radiation therapy improves overall survival of inoperable pancreatic Cancer. Int J Rad Oncol Biol Phys. 2017;99:E184.

Ready to submit your research? Choose BMC and benefit from:

- fast, convenient online submission

- thorough peer review by experienced researchers in your field

- rapid publication on acceptance

- support for research data, including large and complex data types

- gold Open Access which fosters wider collaboration and increased citations

- maximum visibility for your research: over $100 \mathrm{M}$ website views per year

At $\mathrm{BMC}$, research is always in progress.

Learn more biomedcentral.com/submissions 